University of South Carolina

Scholar Commons

12-4-1995

\title{
Structural Characterization of Aluminum Films Deposited on Sputtered-Titanium Nitride/ Silicon Substrate by Metalorganic Chemical Vapor Deposition from Dimethylethylamine alane
}

\author{
Xiaodong Li \\ University of South Carolina - Columbia, lixiao@cec.sc.edu \\ Byoung-Youp Kim \\ Shi-Woo Rhee
}

Follow this and additional works at: https://scholarcommons.sc.edu/emec_facpub

Part of the Chemical Engineering Commons, and the Other Mechanical Engineering Commons

\section{Publication Info}

Published in Applied Physics Letters, Volume 67, Issue 23, 1995, pages \#3426-.

(C)Applied Physics Letters 1995, American Institute of Physics.

Li, X., Kim, B-Y., \& Rhee, S-W. (4 December 1995). Structural Characterization of Aluminum Films Deposited on Sputtered-Titanium Nitride/ Silicon Substrate by Metalorganic Chemical Vapor Deposition from Dimethylethylamine alane. Applied Physics Letters, 67 (230, \#3426. http://dx.doi.org/10.1063/ 1.115268

This Article is brought to you by the Mechanical Engineering, Department of at Scholar Commons. It has been accepted for inclusion in Faculty Publications by an authorized administrator of Scholar Commons. For more information, please contact digres@mailbox.sc.edu. 


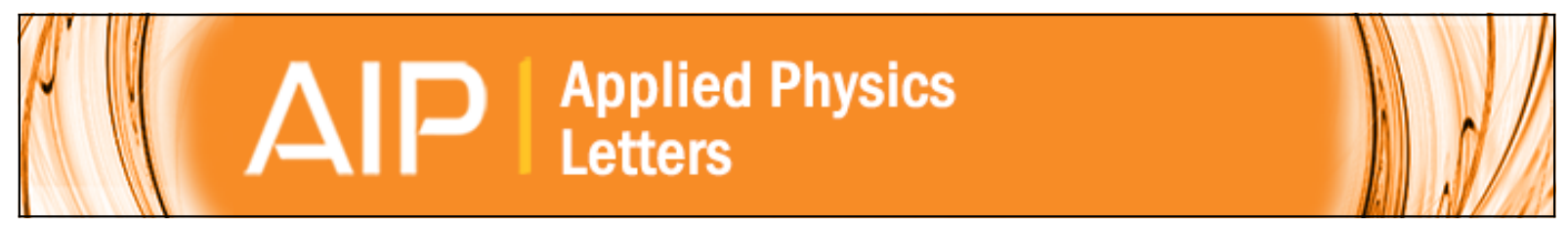

\section{Structural characterization of aluminum films deposited on sputteredtitanium nitride/silicon substrate by metalorganic chemical vapor deposition from dimethylethylamine alane}

Xiaodong Li, ByoungYoup Kim, and ShiWoo Rhee

Citation: Applied Physics Letters 67, 3426 (1995); doi: 10.1063/1.115268

View online: http://dx.doi.org/10.1063/1.115268

View Table of Contents: http://scitation.aip.org/content/aip/journal/apl/67/23?ver=pdfcov

Published by the AIP Publishing

\section{Articles you may be interested in}

Hydrogen plasma pretreatment effect on the deposition of aluminum thin films from metalorganic chemical vapor deposition using dimethylethylamine alane

J. Vac. Sci. Technol. A 17, 1031 (1999); 10.1116/1.581678

Fourier transform infrared diagnostics of gas phase reactions in the metalorganic chemical vapor deposition of aluminum from dimethylethylamine alane

J. Vac. Sci. Technol. A 16, 419 (1998); 10.1116/1.581040

Microstructure and deposition rate of aluminum thin films from chemical vapor deposition with dimethylethylamine alane

Appl. Phys. Lett. 68, 3567 (1996); 10.1063/1.116639

Deposition of AIN at lower temperatures by atmospheric metalorganic chemical vapor deposition using dimethylethylamine alane and ammonia

J. Vac. Sci. Technol. A 13, 711 (1995); 10.1116/1.579812

Liquid source metalorganic chemical vapor deposition of aluminum from triethylamine alane J. Appl. Phys. 69, 2589 (1991); 10.1063/1.348649

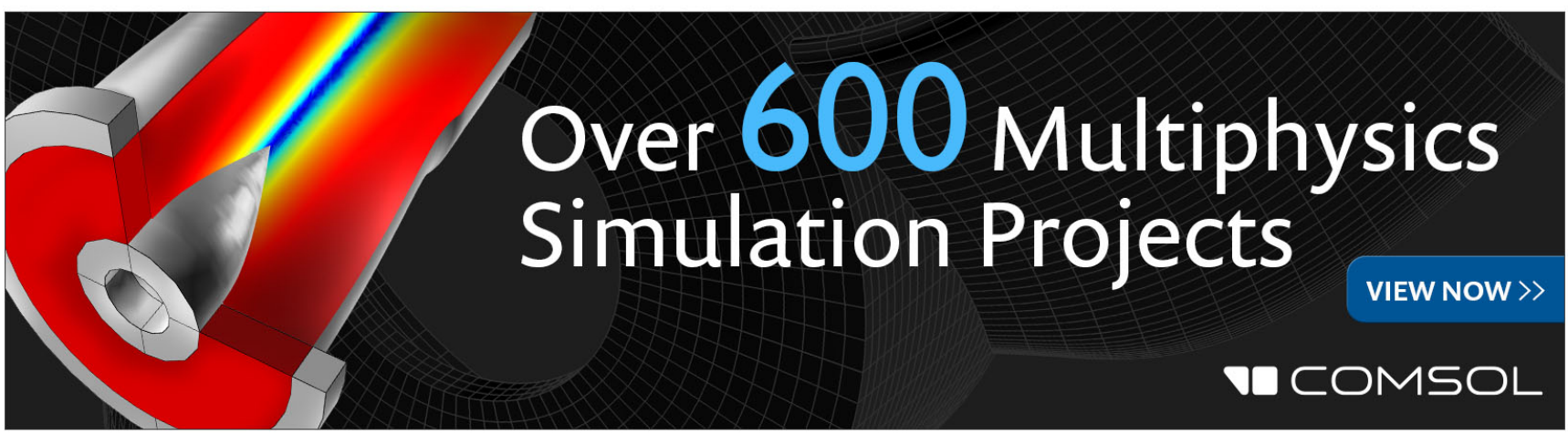




\title{
Structural characterization of aluminum films deposited on sputtered-titanium nitride/silicon substrate by metalorganic chemical vapor deposition from dimethylethylamine alane
}

\author{
Xiaodong Li, Byoung-Youp Kim, and Shi-Woo Rhee ${ }^{\text {a) }}$ \\ Laboratory for Advanced Materials Processing (LAMP), Department of Chemical Engineering, \\ Pohang University of Science and Technology (POSTECH), San 31 Hyoja Dong, Pohang, \\ Kyung-buk 790-784, Republic of Korea
}

(Received 31 July 1995; accepted for publication 27 September 1995)

\begin{abstract}
Al films deposited on sputtered-TiN/Si substrate by metalorganic chemical vapor deposition (MOCVD) from dimethylethylamine alane (DMEAA) were characterized using x-ray diffraction (XRD), Auger electron spectroscopy (AES), atomic force microscopy (AFM), and transmission electron microscopy (TEM). The TiN film sputtered on the Si has a preferred orientation along the growth direction with the $\langle 111\rangle$ of the film parallel to the $\mathrm{Si}\langle 111\rangle$. Sputtering of the TiN film on the $\mathrm{Si}$ induced strains at the interface. The TiN/Si interface is flat while the Al/TiN interface is rough. There exist many dislocations at the $\mathrm{Al} / \mathrm{TiN}$ interface. $\mathrm{The} \mathrm{Al}_{2} \mathrm{O}_{3}$ phase was formed at the $\mathrm{Al} / \mathrm{TiN}$ interface during the early stages of $\mathrm{Al}$ deposition. In the $\mathrm{Al}$ grains, there exist many tangled dislocations and a few $\mathrm{Al}_{2} \mathrm{O}_{3}$ particles. With increasing deposition time, the $\mathrm{Al}$ film surface roughness increases. (C) 1995 American Institute of Physics.
\end{abstract}

Multilevel metallization is an indispensable technique in increasing the device packing density in very large-scale integrated circuits (VLSIs). Al and Al alloy films are widely used for such metallization. Generally, Al is deposited by physical vapor deposition (PVD), however, as aspect ratio increases, it is difficult for PVD to fill via holes of deepsubmicron size. Chemical vapor deposition (CVD) of $\mathrm{Al}$ has the advantages of excellent step coverage and selective growth, which are convenient for such micrometallization. ${ }^{1-4}$

DMEAA is one of the promising candidates for Al CVD because of its relatively high vapor pressure at room temperature (1.5 Torr), its long shelf-life, and its being a liquid and thus providing stable vapor pressure. Moreover, direct $\mathrm{Al}-\mathrm{C}$ bonds are not present in its molecular structure, which helps to prevent carbon contamination. ${ }^{3}$ To improve contact properties, a barrier layer is required for $\mathrm{Al}$ metallization in VLSIs. TiN is frequently used as a barrier layer because of its thermal and chemical stability. Although Al CVD on metal films using DMEAA has been reported, ${ }^{5}$ the structure of the $\mathrm{Al}$ films is still far from clear. We deposited TiN film on $\mathrm{Si}$ as a diffusion barrier with reactive sputtering, and then deposited Al films on the TiN/Si substrate by CVD with DMEAA.

The $\operatorname{Si}(100)$ wafers having $4^{\circ}$ off angle to (100) were used in this study. After a standard cleaning process, TiN film of $500 \mathrm{~nm}$ thickness was formed on the Si by direct current magnetron reactive sputtering in a gas mixture of $\mathrm{Ar}$ and $\mathrm{N}_{2}$. Sputtering parameters were as follows: base pressure 5 $\times 10^{-9}$ Torr, process pressure 3 mTorr, sputtering power 6 $\mathrm{kW}, \mathrm{N}_{2}$ flow rate $60 \mathrm{sccm}$, Ar flow rate $20 \mathrm{sccm}$, substrate heated to $400{ }^{\circ} \mathrm{C}$ during sputtering. Al films were prepared at $190^{\circ} \mathrm{C}$ by CVD with DMEAA. DMEAA was fed into the

${ }^{a)}$ Electronic mail: srhee@ vision.postech.ac.kr reactor with vapor phase mass flow controller without any carrier gas. The base pressure was $1.1 \times 10^{-6}$ Torr and process pressure was 0.15 Torr.

The structures of the TiN and $\mathrm{Al}$ films were analyzed using a Rigaku D-Max 1400 x-ray diffractometer with $\mathrm{Cu} K \alpha$ radiation operating at $50 \mathrm{kV}, 150 \mathrm{~mA}$. The depth profiles of elements $\mathrm{Al}, \mathrm{O}, \mathrm{N}, \mathrm{Si}$, and $\mathrm{Ti}$ were obtained by a Perkin-Elmer PHI 600 scanning Auger multiprobe. The surface morphology of the TiN and $\mathrm{Al}$ films was observed using

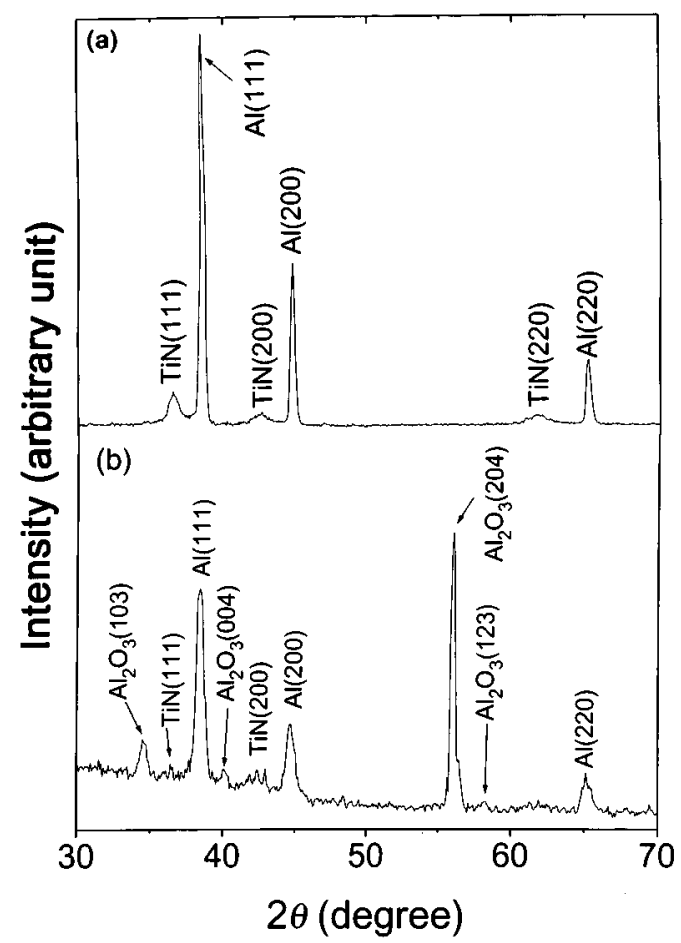

FIG. 1. XRD spectra of the Al films deposited on the TiN/Si substrate for (a) 15 and (b) 1 min, respectively. 


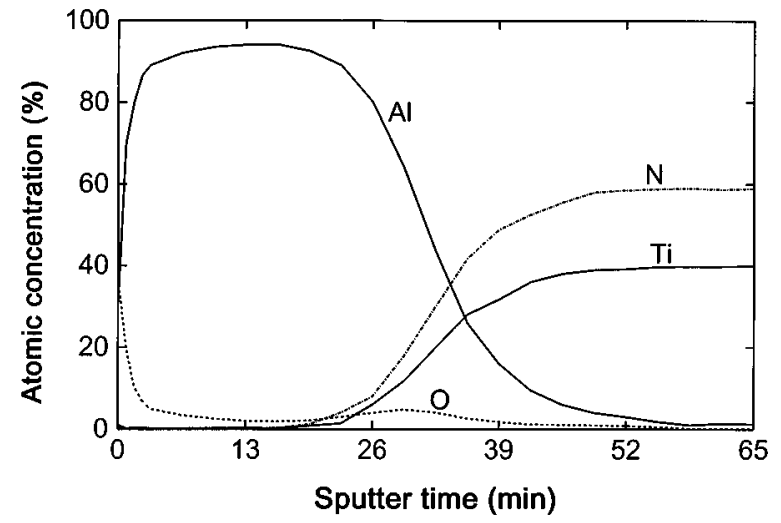

FIG. 2. Typical AES depth profiles from an Al film deposited on the TiN/Si substrate.

an Autoprobe-CP model atomic force microscope. Crosssectional specimens for TEM were first glued face to face, cut, then ground, dimpled, and thinned by ion milling. TEM observations were conducted using a JEOL JEM-200CX transmission electron microscope operating at $100 \mathrm{kV}$.

Figure 1 shows the XRD spectra of the Al films deposited on the TiN/Si substrate for 1 and $15 \mathrm{~min}$, respectively. The thickness of the Al films deposited on the TiN/Si substrate for 1 and $15 \mathrm{~min}$ was estimated to be about 50 and $1000 \mathrm{~nm}$, respectively, by weight measurement. The TiN film sputtered on Si exhibits strong (111) orientation while the Al films deposited on the TiN/Si substrate show random orientation. This is not in agreement with the results of Al films sputtered on the sputtered-TiN(111) films, where the Al films give (111) orientation. ${ }^{6}$ The $\mathrm{Al}$ film deposited on the TiN/Si substrate for 1 min shows several peaks from $\mathrm{Al}_{2} \mathrm{O}_{3}$ in addition to the peaks of both $\mathrm{Al}$ and $\mathrm{TiN}$ while the $\mathrm{Al}$ film deposited on the TiN/Si substrate for $15 \mathrm{~min}$ does not. The $\mathrm{Al}_{2} \mathrm{O}_{3}$ phase is not likely to be from surface native oxide because it was not detected by XRD when the film was thick. This indicates that the $\mathrm{Al}_{2} \mathrm{O}_{3}$ phase or intermediate layer formed during the early stages of $\mathrm{Al}$ deposition.

Figure 2 shows typical AES depth profiles from an $\mathrm{Al}$ film deposited on the TiN/Si substrate. A small oxygen peak was observed at the $\mathrm{Al} / \mathrm{TiN}$ interface near the Al film side. This suggests that Al-O compounds formed at the Al/TiN interface, in good agreement with the XRD results. A Ti-O compound layer was reported to exist on the TiN film surface. ${ }^{7}$ The formation of the $\mathrm{Al}_{2} \mathrm{O}_{3}$ phase at the $\mathrm{Al} / \mathrm{TiN}$ interface suggests that during $\mathrm{Al}$ CVD $\mathrm{Ti}-\mathrm{O}$ compounds reacted with $\mathrm{Al}$, forming the $\mathrm{Al}-\mathrm{O}$ compounds. The effect of temperature and other operating variables on the formation of alumina at the interface is not yet known.

Figure 3 shows the AFM images of the TiN film, and the Al films deposited on the TiN/Si substrate for 1 and $15 \mathrm{~min}$, respectively. The TiN and $\mathrm{Al}$ films exhibit rugged surface morphology. The rugged mountains of the TiN film distribute uniformly while those of both Al films do not. With increasing deposition time, the Al film surface roughness increases. The average diameters of the rugged mountains of the TiN film, and the Al films deposited on the TiN/Si substrate for 1

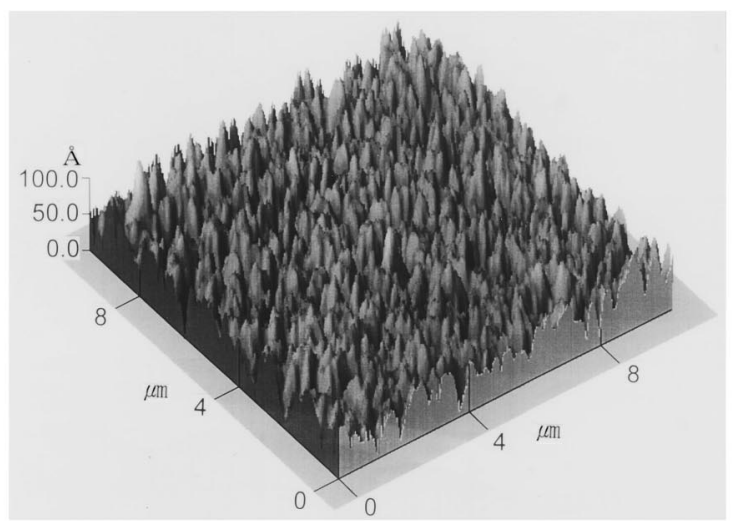

(a)

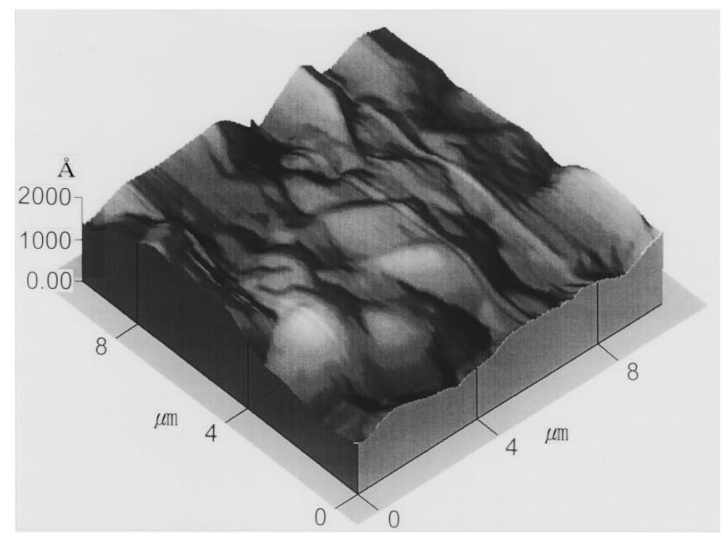

(b)

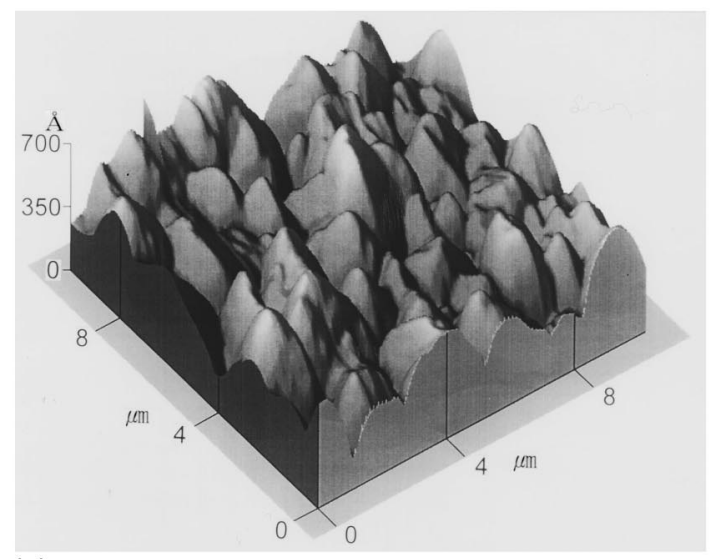

(c)

FIG. 3. AFM images of (a) the TiN film, and the Al films deposited on the TiN/Si substrate for (b) 15 and (c) 1 min, respectively.

and $15 \mathrm{~min}$, are 1020,2160 , and $5630 \mathrm{~nm}$, respectively. From the AFM results, however, it is difficult to determine the structure of the TiN and Al films.

Figure 4 shows the bright field cross-sectional TEM images of the $\mathrm{Al}$ film deposited on the TiN/Si substrate for 15 min and the $\mathrm{Al} / \mathrm{TiN}$ interface, respectively. Good sections with homogenous thickness were obtained with the TiN and Al films [Fig. 4(a)]. The thickness of the Al film was found to be about $1000 \mathrm{~nm}$, and that of the TiN film was found to be about $500 \mathrm{~nm}$. The TiN film was found to be made up of very small needlelike grains $\sim 20 \mathrm{~nm}$ in width and $200 \mathrm{~nm}$ in length, which grow in the direction inclined to the $\mathrm{Si}$ at an 

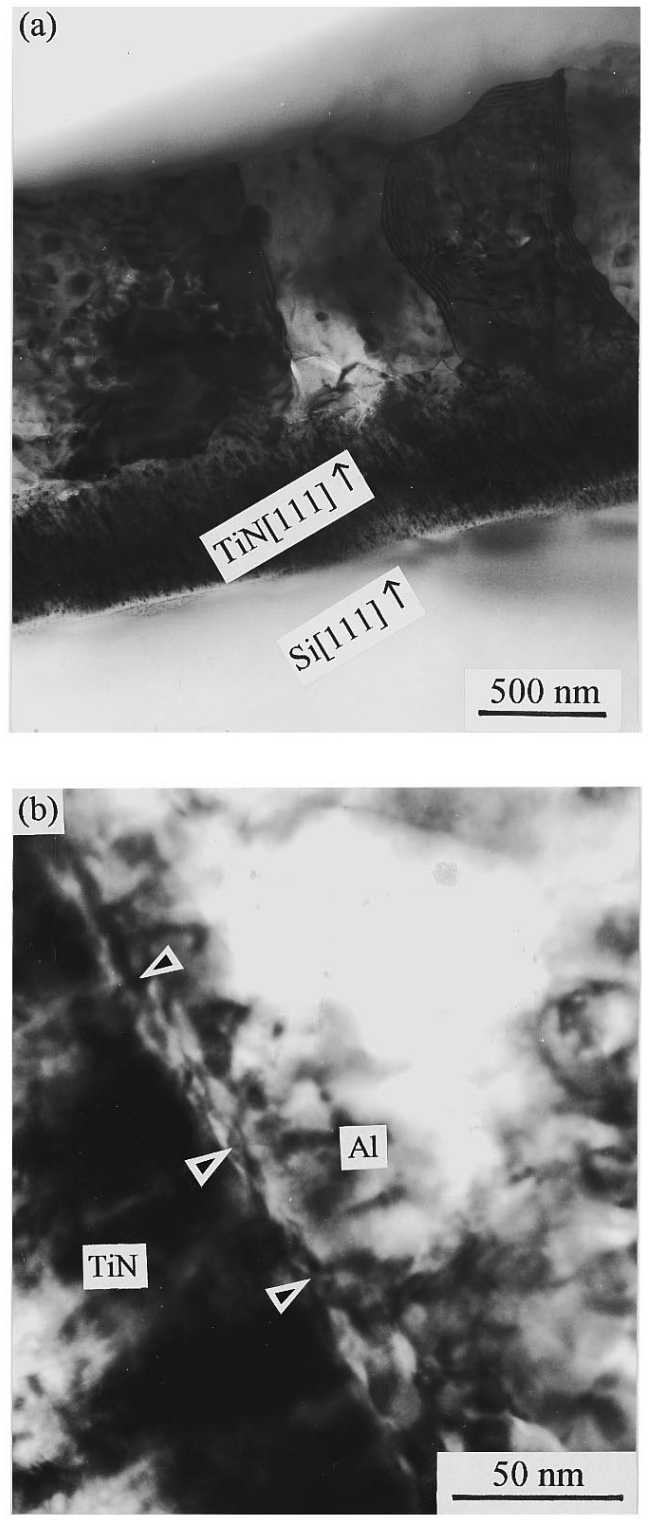

FIG. 4. Bright field cross-sectional TEM images of (a) the Al film deposited on the TiN/Si substrate for $15 \mathrm{~min}$ and (b) the Al/TiN interface, respectively.

angle of about $66^{\circ}$. This direction is parallel to the $\mathrm{Si}\langle 111\rangle$. From the XRD results, it is suggested that the growth direction of the TiN film is $\langle 111\rangle$. Therefore, there is a preferred orientation of the TiN film along the growth direction with the film $\langle 111\rangle$ parallel to the $\mathrm{Si}\langle 111\rangle$. This is probably because atomic arrangement and interatomic distance of the TiN(111) plane are close to those of the $\mathrm{Si}(111)$. Obvious changes in contrast were observed in the Si near the interface [Fig. 4(a)], indicating that the sputtering of TiN film on the $\mathrm{Si}$ induced strains at the interface. The Al/TiN interface is relatively rough, and there exist many dislocations [Fig. 4(b)]. An intermediate layer indicated by the arrow in Fig. 4(b) seems to exist at the Al/TiN interface, which might be the $\mathrm{Al}_{2} \mathrm{O}_{3}$ phase found by XRD and AES. The Al grains were found to have elongated blocklike shape $\sim 600 \mathrm{~nm}$ in width and $930 \mathrm{~nm}$ in length. Some small Al grains, which were formed at the nucleation stage, were found near the interface. In the $\mathrm{Al}$ grains, there exist many tangled dislocations, and a few small particles with a diameter of about $50 \mathrm{~nm}$ which were identified as $\mathrm{Al}_{2} \mathrm{O}_{3}$ phase by selected area diffraction analysis. $\mathrm{Al}_{2} \mathrm{O}_{3}$ particles cannot nucleate and grow to such size in the $\mathrm{Al}$ grains within $30 \mathrm{~min}$ at $190{ }^{\circ} \mathrm{C}$. It was also found that there is not any definite orientational relationship between the $\mathrm{Al}_{2} \mathrm{O}_{3}$ particles and $\mathrm{Al}$ matrix. Therefore, a possible reason for the existence of $\mathrm{Al}_{2} \mathrm{O}_{3}$ particles within the $\mathrm{Al}$ grains is that $\mathrm{Al}_{2} \mathrm{O}_{3}$ particles formed in gas phase because of residual $\mathrm{O}_{2}$ or $\mathrm{H}_{2} \mathrm{O}$ and then deposited together with $\mathrm{Al}$ onto specimen surface. DMEAA is unstable in the atmosphere and it readily decomposes into alumina when exposed to air. Because the volume fraction of $\mathrm{Al}_{2} \mathrm{O}_{3}$ particles is small, it is impossible to detect them by XRD. The existence of $\mathrm{Al}_{2} \mathrm{O}_{3}$ particles in the $\mathrm{Al}$ grains is also one of the reasons why there exist many tangled dislocations in the grains. Compared with the AFM results, it was found that the rugged mountains in the AFM images do not correspond to the grains. It is desirable that grain size should be large and uniformly distributed. Also, the film should be free from impurities. Other researchers showed that impurities like hydrogen, ${ }^{8}$ nitrogen, ${ }^{9}$ and oxygen ${ }^{10}$ have bad effects on the migration resistance of metal lines.

In summary, the TiN film sputtered on the Si has a preferred orientation along the growth direction with the $\langle 111\rangle$ of the film parallel to the Si $\langle 111\rangle$. Sputtering of the TiN film on the $\mathrm{Si}$ induced strains at the interface. The TiN/Si interface is flat while the $\mathrm{Al} / \mathrm{TiN}$ interface is rough. There exist many dislocations at the $\mathrm{Al} / \mathrm{TiN}$ interface. $\mathrm{Al}_{2} \mathrm{O}_{3}$ phase formed at the $\mathrm{Al} / \mathrm{TiN}$ interface during the early stages of $\mathrm{Al}$ deposition. In the $\mathrm{Al}$ grains, there exist many tangled dislocations and a few $\mathrm{Al}_{2} \mathrm{O}_{3}$ particles. With increasing deposition time, the $\mathrm{Al}$ film surface roughness increases.

This research was supported by LG Semiconductor Co. and support of Engineering Research Center for Interface Science and Technology of Materials is also acknowledged.

${ }^{1}$ N. Takeyasu, Y. Kawano, E. Kondoh, T. Katagiri, H. Yamamoto, H. Shinriki, and T. Ohta, Jpn. J. Appl. Phys. 33, 424 (1994).

${ }^{2}$ J. Drucker, R. Sharma, and K. Weiss, J. Appl. Phys. 76, 8198 (1994).

${ }^{3}$ Y. Matsumiya, K. Kitahara, N. Ohtsuka, and K. Nakajima, Jpn. J. Appl. Phys. 34, L17 (1995).

${ }^{4}$ M. E. Gross, C. G. Fleming, K. P. Cheung, and L. A. Heimbrook, J. Appl. Phys. 69, 2589 (1991).

${ }^{5}$ M. G. Simmonds, I. Taupin, and W. L. Gladfelter, Chem. Mater. 6, 935 (1994).

${ }^{6}$ T. Kaizuka, H. Shinriki, N. Takeyasu, and T. Ohta, Jpn. J. Appl. Phys. 33, 470 (1994).

${ }^{7}$ S. R. Ryu, D. S. Shin, J. E. Oh, J. S. Choi, S. H. Paek, S. I. Lee, J. K. Lee, T. U. Sim, J. G. Lee, and G. T. Sheng, Appl. Phys. Lett. 62, 579 (1993).

${ }^{8}$ K. Tokunaga and K. Sugawara, J. Electrochem. Soc. 138, 176 (1991).

${ }^{9}$ J. Klema, R. Pyle, and E. Domangue, Proceedings of the 22nd International Reliability Physics Symposium (IEEE, New York, 1990), p. 216

${ }^{10} \mathrm{H}$. Okabayashi and K. Aizawa, Proceedings of the 2nd International Stress-Induced Phenomena in Metallization (AIP, New York, 1994), p. 33. 